\title{
EFEITOS DA PRECIPITAÇÃO PLUVIAL, DA UMIDADE RELATIVA DO AR E DE EXCESSO E DÉFICIT HÍDRICO DO SOLO NO PESO DO HECTOLITRO, NO PESO DE MIL GRÃOS E NO RENDIMENTO DE GRÃOS DE TRIGO
}

\author{
Eliana Maria GUARIENTI *, César Francisco CIACCO', Gilberto Rocca da CUNHA, \\ Leo de Jesus Antunes DEL DUCA", Celina Maria de Oliveira CAMARGO
}

\begin{abstract}
RESUMO
Cerca de $90 \%$ da produção de trigo no Brasil está localizada nos estados do Paraná, do Rio Grande do Sul e de Santa Catarina. Nesses estados, a variabilidade climática é muito expressiva, tornando a produção tritícola uma atividade de risco e fazendo com que o decréscimo da produção e da produtividade de trigo seja objeto de questionamento de grande número de investigadores. Este trabalho teve por objetivo verificar a influência da precipitação pluvial, da umidade relativa do ar e de excesso e déficit hídrico do solo no peso do hectolitro, peso de mil grãos e rendimento de grãos. Foram usados dados de experimentos com a cultivar de trigo Embrapa 16, conduzidos durante os anos de 1990 a 1998, em sete locais do Rio Grande do Sul e em quatro locais de Santa Catarina. A análise estatística realizada foi correlação múltipla. Verificou-se que: a) a precipitação pluvial e o excesso hídrico do solo afetaram negativamente o peso do hectolitro, peso de mil grãos e rendimento de grãos, e a umidade relativa do ar influenciou tanto positiva quanto negativamente essas variáveis; b) o déficit hídrico do solo afetou positivamente o peso do hectolitro, peso de mil grãos e rendimento de grãos após a maturação fisiológica, isto é, nos dez primeiros dias anteriores à colheita, e negativamente nos demais períodos.

Palavras-chave: trigo; qualidade; meteorologia.
\end{abstract}

\section{SUMMARY}

EFFECTS OF RAINFALL, RELATIVE HUMIDITY AND WATER EXCESS AND DEFICIT ON TEST WEIGHT, THOUSAND KERNEL WEIGHT, AND GRAIN YIELD OF WHEAT. About $90 \%$ of the wheat production in Brazil is located in Paraná, Rio Grande do Sul and Santa Catarina states. In these states there is a considerable climatic variability and consequently wheat production becomes a risky activity. Therefore, the decrease of wheat production and grain yield has been analyzed by a great number of investigators. This work aimed to verify the influence of rainfall, relative humidity, and water excess and deficit on test weight, thousand kernel weight, and grain yield of wheat. Data of Embrapa 16 wheat cultivar, obtained during the 1990-98 period, in seven Rio Grande do Sul state locations, and in four in Santa Catarina were used. Statistical analysis used was multiple correlation. It was verified that: a) rainfall and water excess in soil affected negative test weight, thousand kernel weight, and grain yield of wheat, and relative humidity influenced positively as much as negatively such variables; b) soil water deficit affected positive test weight, thousand kernel weight, and the grain yield of wheat after the physiological maturation, that is, during the first ten days previous to the harvest of the crop, and negative for the other periods.

Keywords: wheat; quality; meteorology.

\section{1 - INTRODUÇÃO}

Os principais problemas climáticos da região tritícola sul-brasileira (Rio Grande do Sul, Santa Catarina e sul do Paraná) são: excesso de umidade relativa do ar, em setembro-outubro, ocorrência de geadas no espigamento, chuvas na colheita e granizo [28].

O decréscimo da produção e da produtividade de trigo em razão da distribuição e da quantidade de precipitação pluvial têm sido objeto de pesquisa de investigadores, como: DEL DUCA [14], HADJICHRISTODOULOU [18], KOLDERUP [20], LUZ [21], SEIF \& PEDERSON [32], WILLIAMS [39], entre outros.

Recebido para publicação em 23/07/2002. Aceito para publicação em 31/08/2005 (000946).

Centro Nacional de Pesquisa de Trigo (CNPT) - EMBRAPA. Caixa Postal: 451. CEP: 99001-970, Passo Fundo-RS. E-mail: eliana@cnpt.embrapa.br/cunha@cnpt.embrapa.br

Departamento de Tecnologia de Alimentos, Faculdade de Engenharia de Alimentos, Universidade Estadual de Campinas (UNICAMP). Caixa Postal: 6121. CEP: 13083-970, Campinas-SP. Email: ciacco@obelix.unicamp.br

A quem a correspondência deve ser enviada.
MELLADO, MALDONADO \& GRANGER [22] estudaram, em três anos de experimento, o efeito de chuva após a maturação de trigo sobre a produção de grãos, o peso do hectolitro, a dureza e o teor de proteínas nos grãos, o rendimento de farinha, o valor de sedimentação, a farinografia e a panificação (volume, textura e cor da crosta). Esses autores concluíram que o peso do hectolitro foi a única variável afetada, nas condições do experimento, chegando à redução de 5\% comparativamente à testemunha. No modelo de regressão linear, o coeficiente de determinação $\mathrm{R}^{2}$ apresentou valores de 0,85, 0,93 e 0,96 para os anos de 1981, 1982 e 1983, respectivamente.

HIRANO [19] estudou o efeito da chuva no período de maturação na qualidade de trigo no Japão e concluiu que chuvas no período inicial da maturação afetam, principalmente, características quantitativas dos grãos, enquanto chuva no fim da maturação causa decréscimo nas características de qualidade de trigo. $\mathrm{O}$ autor relatou que chuvas no início da maturação reduziram o peso de mil grãos e peso do hectolitro, incrementaram o teor de cinzas do grão, e promoveram decréscimo no rendimento de farinha e no escore de moagem. No fim da maturação, foi observada diminuição nos parâmetros obtidos nos testes de farinografia (exceto a absorção de água), de exten- 
sografia e de amilografia.

Tendo em vista a multiplicidade de fatores climáticos que afetam a produção e a produtividade de trigo, CUNHA [6] mencionou que a forma mais eficiente que o produtor dispõe para reduzir esses riscos é o emprego de práticas de manejo das culturas, tais como escolha de cultivar e de época de semeadura, da densidade e do arranjo de plantas, dos manejos de água e de resíduos na superficie, da fertilização etc. Essas práticas objetivam a minimizar o impacto das flutuações climáticas extremas e a otimização do aproveitamento das condições climáticas mais freqüentes.

O conhecimento dos riscos de natureza climática que interferem na qualidade de trigo produzido no Sul do Brasil pode amenizar o risco de perdas econômicas, além de constituir poderoso auxiliar nas tomadas de decisão do produtor e dos formuladores de politicas agrícolas e de contribuir para a oferta de matérias-primas adequadas às necessidades das indústrias brasileiras. Além disso, o conhecimento dos períodos críticos em que as variáveis meteorológicas podem afetar a qualidade industrial de trigo possibilita a adoção de práticas de manejo que visam à otimizar o cultivo de trigo e à melhoria da qualidade dessa matéria-prima.

O presente trabalho teve por objetivos verificar a influência da precipitação pluvial, da umidade relativa do ar e de déficit e excesso hídrico do solo no peso do hectolitro, peso de mil grãos e rendimento de grãos, sob condições da região tritícola sul-brasileira.

\section{2 - MATERIAL E MÉTODOS}

Foram usadas amostras de experimentos com a cultura de trigo, conduzidos por órgãos oficiais de pesquisa, realizados no Rio Grande do Sul e em Santa Catarina, durante os anos de 1990 a 1998. Essas informações são apresentadas na Tabela 1.

A cultivar usada foi Embrapa 16, resultante do cruzamento duplo Hulha Negra/CNT 7 / /Amigo/CNT 7 [15].
As amostras analisadas compunham os ensaios Preliminar em Rede, Sul-Brasileiro de Trigo, Regional de Linhagens de Trigo e Estadual de Cultivares de Trigo, conduzidos segundo o delineamento experimental de blocos ao acaso, com quatro repetições. A densidade de semeadura usada foi de 300 a 330 sementes viáveis $/ \mathrm{m}^{2}$. A área de cada parcela foi de cinco metros quadrados (cinco fileiras de cinco metros de comprimento, espaçadas vinte centimetros), sendo a área útil de três metros quadrados (três fileiras centrais).

A correção da acidez e a fertilização do solo, em cada local, foram realizadas conforme as recomendações da SOCIEDADE BRASILEIRA DE CIÊNCIA DO SOLO [33], para uma expectativa de produtividade superior a $2.000 \mathrm{~kg} / \mathrm{ha}$. A fertilização com nitrogênio em cobertura foi realizada aos 30 a 45 dias após a emergência, em todos os experimentos.

A colheita, nos diferentes locais, foi realizada manualmente ou com colhedora de parcelas.

Os resultados de rendimento de grãos usados neste trabalho foram publicados, originalmente, pelos seguintes autores:

- Ensaios Estaduais de Cultivares de Trigo, conduzidos no Rio Grande do Sul em 1992, 1997 e 1998 por ZANOTELLI et al. [40, 41, 42]; em 1993 por WALDMAN et al. [38]; e em 1994 por WALDMAN \& CAUMO [37];

- Ensaios Regionais de Linhagens de Trigo, conduzidos no Rio Grande do Sul em 1994 e 1996 por SVOBODA et al. [34, 35];

- $\quad$ Ensaios Sul-Brasileiros de Trigo, conduzidos no Rio Grande do Sul em 1990, 1991, 1994, 1995, 1996 por MOREIRA [23, 24, 25, 26, 27];

- Ensaios Sul-Brasileiros de Trigo e Estaduais de Cultivares de Trigo conduzidos em Santa Catarina em 1991, 1993, 1994, 1995, 1996, 1997, e em 1998, por DÁVALOS et al. [7, 8, 9, 10, 11, 12, 13].

TABELA 1 - Região tritícola, local, ano de plantio e ensaio em que foram produzidas as amostras de trigo Embrapa 16

\begin{tabular}{|c|c|c|c|c|c|c|c|c|c|c|}
\hline \multirow{2}{*}{$\begin{array}{l}\text { Região } \\
\text { triticola }\end{array}$} & \multirow{2}{*}{$\begin{array}{l}\text { Local de } \\
\text { plantio }\end{array}$} & \multicolumn{9}{|c|}{ Ano de plantio } \\
\hline & & 1990 & 1991 & 1992 & 1993 & 1994 & 1995 & 1996 & 1997 & 1998 \\
\hline I & Vacaria & - & ESB & EEC & EPRII & ER & ESB & ESB & EEC & - \\
\hline II & $\begin{array}{l}\text { Lagoa } \\
\text { Vermelha }\end{array}$ & - & - & - & - & ESB & ESB & ESB & EEC & EEC \\
\hline III & $\begin{array}{l}\text { Passo } \\
\text { Fundo }\end{array}$ & ESB & ESB & EEC & EEC & EEC & ESB & ESB & EEC & EEC \\
\hline IV & $\begin{array}{l}\text { Santo } \\
\text { Ângelo }\end{array}$ & - & ESB & - & EEC & EEC & ESB & ESB & - & - \\
\hline V & São Borja & - & - & - & - & ESB & ESB & - & - & - \\
\hline VII & Pelotas & - & ESB & - & - & - & ESB & ER & - & EEC \\
\hline VIII & Piratini & - & ESB & - & - & EEC & ESB & ER & - & EEC \\
\hline $3 \mathrm{~A}$ & $\begin{array}{l}\text { Campos } \\
\text { Novos }\end{array}$ & - & ESB & - & EEC & EEC & ESB & ESB & EEC & - \\
\hline 3B & Canoinhas & - & - & - & EEC & - & ESB & - & - & - \\
\hline $3 \mathrm{C}$ & $\begin{array}{l}\text { Abelardo } \\
\text { Luz }\end{array}$ & - & ESB & - & EEC & EEC & ESB & ESB & - & - \\
\hline $3 \mathrm{C}$ & Chapecó & - & - & - & EEC & - & ESB & ESB & EEC & EEC \\
\hline
\end{tabular}


As quatro repetições de cada amostra de grãos foram misturadas constituindo, dessa forma, amostras compostas, que foram analisadas no Laboratório de Qualidade Industrial de Trigo, da Embrapa Trigo, em que foram realizadas as análises de peso do hectolitro, medido pelo aparelho Dalle Molle, segundo método descrito pelo fabricante [1], sendo os resultados padronizados para $13 \%$ de umidade, mediante cálculo de perda/ganho de umidade descrito por PUZZI [29], e de peso de mil grãos, segundo método descrito por BRASIL [4];

As observações meteorológicas eram provenientes de onze Estações do Instituto Nacional de Meteorologia/8 ${ }^{\circ}$ Distrito de Meteorologia (INMET/8 ${ }^{\circ}$ DISME), da FEPAGRO (Fundação Estadual de Pesquisa Agropecuária), no Rio Grande do Sul, e da EPAGRI (Empresa de Pesquisa Agropecuária e Extensão Rural de Santa Catarina S.A.), em Santa Catarina.

Os municípios de Piratini e de Santo Ângelo, no Rio Grande do Sul, e de Canoinhas, em Santa Catarina, não possuem estações meteorológicas, portanto, foram usados registros de estações meteorológicas de municipios vizinhos, pertencentes à mesma região tritícola, ou seja, respectivamente, Encruzilhada do Sul, Santa Rosa e Major Vieira.

Foram empregadas observações meteorológicas diárias até oitenta dias antes da colheita dos diferentes ensaios de trigo. As variáveis meteorológicas analisadas foram:

- $\quad$ precipitação (mm) - usado Pluviômetro tipo "Ville de Paris" ou Pluviógrafo tipo Hellmann, localizado a $1,5 \mathrm{~m}$ sobre o nível do solo;

- umidade relativa do ar (\%) - usou-se Psicrômetro, localizado no abrigo meteorológico padrão a $1,5 \mathrm{~m}$ sobre o nivel do solo.

Foi usado o método de cálculo de balanço hídrico desenvolvido por THORNTHWAITE \& MATHER [36], que consiste no cotejo entre precipitação pluvial e temperatura média, considerando-se 75 milimetros a capacidade de armazenamento de água no solo. Os cálculos do balanço hídrico climático foram realizados por meio de planilhas em ambiente Excel ${ }^{\mathrm{TM}}$, desenvolvidas por ROLIM, SENTELHAS \& BARBIERI [31]. Os valores empregados neste trabalho foram déficit e excesso hídrico do solo.

Foi realizada análise de correlação linear para fins de verificar uma possivel relação entre as variáveis meteorológicas precipitação pluvial, umidade relativa do ar, déficit e excesso hídrico do solo e as variáveis rendimento de grãos de trigo, peso do hectolitro e peso de mil grãos. Para tanto, foram criados quatro tipos de arquivos que incluem dados do somatório de precipitação pluvial, média da umidade relativa, divididos em periodos:

$\left.1^{\circ}\right)$ dezesseis períodos divididos de cinco em cinco dias anteriores à colheita;

$2^{\underline{o}}$ ) oito períodos divididos de dez em dez dias anterio- res à colheita;

$3^{\text {o) }}$ cinco períodos divididos de quinze em quinze dias anteriores à colheita; e,

$\left.4^{\circ}\right)$ quatro períodos divididos de vinte em vinte dias anteriores à colheita.

\section{3 - RESULTADOS E DISCUSSÃo}

As condições meteorológicas, fisicas e fitossanitárias prevalecentes durante a condução dos ensaios nos diferentes locais configuram as amostras como de origem observacional, ou seja, provenientes de condições parcialmente controladas. Dessa forma, é esperado que os coeficientes de correlação (r) não sejam muito elevados.

Considerando-se o universo de fatores que afetam a expressão da qualidade industrial e do rendimento de grãos de trigo, a ocorrência de correlações significativas pode ser considerada relevante, apesar dos baixos valores.

Nas Tabelas 2 a 5 são apresentados os resultados das correlações múltiplas entre variáveis meteorológicas e peso do hectolitro, peso de mil grãos e rendimento de grãos de trigo.

Como pode ser observado nessas tabelas, o somatório da precipitação pluvial afetou negativamente a maioria das características de qualidade de trigo, variando a predominância dessa influência conforme período considerado.

Para peso do hectolitro, foram obtidas as seguintes associações negativas com somatório da precipitação pluvial: no periodo de um a cinco $(r=-0,30)$, vinte e seis a trinta $(\mathrm{r}=-0,36)$, um a de $(\mathrm{r}=-0,32)$, onze a vinte dias $(\mathrm{r}=-0,30)$, vinte e um a trinta $(\mathrm{r}=-0,40)$, um a quinze $(r=-0,30)$, dezesseis a trinta $(r=-0,37)$ e um a vinte $(\mathrm{r}=-0,34)$ dias anteriores à colheita, considerando o nível de $5 \%$ de probabilidade (Tabelas 2 a 5).

Quanto ao peso de mil grãos, o somatório da precipitação pluvial correlacionou-se negativamente com essa característica de qualidade, nos seguintes períodos: um a cinco $(r=-0,57)$, vinte e seis a trinta $(r=-0,46)$, quarenta e um a quarenta e cinco $(r=-0,32)$, vinte e um a trinta dias $(r=-0,44)$, quarenta e um a cinqüenta $(r=-0,31)$, um a quinze $(r=-0,31)$, dezesseis a trinta $(r=-0,37)$, trinta e um a quarenta e cinco dias $(r=-0,32)$, um a vinte $(\mathrm{r}=-0,32)$ e vinte e um a quarenta dias $(\mathrm{r}=-0,33)$ dias anteriores à colheita (Tabelas 2 a 5).

Para rendimento de grãos, o somatório da precipitação pluvial influenciou negativamente os seguintes períodos antes da colheita: onze a quinze $(r=-0,33)$, vinte e um a vinte e cinco $(\mathrm{r}=-0,30)$, vinte e seis a trinta $(\mathrm{r}=-0,29)$, onze a vinte $(\mathrm{r}=0,35)$, vinte e um a trinta $(\mathrm{r}=-0,37)$ e dezesseis a trinta $(\mathrm{r}=-0,35)$ dias (Tabelas $2 a$ 5).

Observou-se que o excesso hídrico do solo afetou negativamente o peso do hectolitro nos períodos de um a 
Efeitos de fatores ligados a água no trigo, Guarienti et al.

TABELA 2 - Sumário das correlações múltiplas $(p<0,05)$ entre variáveis meteorológicas e características de qualidade e rendimento de trigo Embrapa 16, no periodo de um a oitenta dias que antecedem a colheita, divididos em cinco em cinco dias, em quinze em quinze e em vinte em vinte dias

\begin{tabular}{|c|c|c|c|c|c|c|c|c|c|c|c|c|}
\hline \multirow{2}{*}{$\begin{array}{c}\text { Variável } \\
\text { meteorológica }\end{array}$} & \multicolumn{12}{|c|}{ Período que antecede a colheita (em dias) } \\
\hline & $1-5$ & $11-15$ & 21-25 & $26-30$ & $36-40$ & $41-45$ & $56-60$ & $1-15$ & $16-30$ & $31-45$ & $1-20$ & $21-40$ \\
\hline & \multicolumn{12}{|c|}{ Peso do hectolitro } \\
\hline Precipitaçấo pluvial & $-0,30$ & - & - & $-0,36$ & - & - & - & $-0,30$ & $-0,37$ & - & $-0,34$ & - \\
\hline \multirow[t]{2}{*}{ Umidade relativa do ar } & - & - & - & - & - & - & 0,30 & - & - & - & - & - \\
\hline & \multicolumn{12}{|c|}{ Peso de mil grãos } \\
\hline Precipitação pluvial & $-0,57$ & - & - & $-0,46$ & - & $-0,32$ & - & $-0,31$ & $-0,37$ & $-0,32$ & $-0,32$ & $-0,33$ \\
\hline \multirow[t]{2}{*}{ Umidade relativa do ar } & $-0,39$ & - & - & - & $-0,32$ & - & - & - & - & - & - & $-0,35$ \\
\hline & \multicolumn{12}{|c|}{ Rendimento de grãos } \\
\hline Precipitação pluvial & - & $-0,33$ & $-0,30$ & $-0,29$ & - & - & - & - & $-0,35$ & - & - & - \\
\hline Umidade relativa do ar & - & - & - & - & - & - & - & - & - & - & - & - \\
\hline
\end{tabular}

TABELA 3 - Sumário das correlações múltiplas $(p<0,05)$ entre variáveis meteorológicas e características de qualidade e rendimento de trigo Embrapa 16, no período de um a oitenta dias que antecedem a colheita, divididos em dez em dez dias

\begin{tabular}{|c|c|c|c|c|c|c|c|c|}
\hline \multirow[t]{2}{*}{ Variável meteorológica } & \multicolumn{8}{|c|}{ Periodo que antecede a colheita (em dias) } \\
\hline & $1-10$ & $11-20$ & $21-30$ & $31-40$ & $41-50$ & $51-60$ & $61-70$ & $71-80$ \\
\hline $\begin{array}{l}\text { Precipitação pluvial } \\
\text { Umidade relativa do ar } \\
\text { Déficit hídrico do solo } \\
\text { Excesso hidrico do solo }\end{array}$ & $\begin{array}{c}-0,32 \\
- \\
-0,41\end{array}$ & $\begin{array}{c}-0,30 \\
- \\
-0,30\end{array}$ & $\begin{array}{c}\text { Peso do } h \\
-0,40 \\
-0,27 \\
-\end{array}$ & $:$ & $-0,41$ & $\begin{array}{c}- \\
0,32 \\
-0,56\end{array}$ & $:$ & $\begin{array}{c}- \\
- \\
-0,35\end{array}$ \\
\hline $\begin{array}{l}\text { Precipitação pluvial } \\
\text { Umidade relativa do ar } \\
\text { Déficit hidrico do solo } \\
\text { Excesso hídrico do solo }\end{array}$ & 0,34 & $\begin{array}{l}- \\
-\end{array}$ & $\begin{array}{c}\text { Peso de } n \\
-0,44 \\
-0,36 \\
- \\
-\end{array}$ & $\begin{array}{c}- \\
-0,36\end{array}$ & $\begin{array}{c}-0,31 \\
- \\
- \\
-\end{array}$ & $\begin{array}{c}- \\
- \\
-0,35\end{array}$ & $:$ & $:$ \\
\hline $\begin{array}{l}\text { Precipitação pluvial } \\
\text { Umidade relativa do ar } \\
\text { Déficit hidrico do solo } \\
\text { Excesso hídrico do solo }\end{array}$ & $\therefore$ & $\begin{array}{c}-0,35 \\
- \\
- \\
-0,34 \\
\end{array}$ & $\begin{array}{c}\text { Rendiment } \\
-0,37 \\
- \\
- \\
\end{array}$ & $\begin{array}{l}\text { os } \\
:- \\
- \\
-\end{array}$ & $-0,29$ & 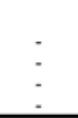 & $\begin{array}{c}- \\
- \\
-0,31 \\
\end{array}$ & $\therefore$ \\
\hline
\end{tabular}

TABELA 4 - Sumário das correlações múltiplas $(\mathrm{p}<0,05)$ entre variáveis meteorológicas e características de qualidade e rendimento de trigo Embrapa 16, no período de um a oitenta dias que antecedem a colheita, divididos em quinze em quinze dias

\begin{tabular}{|c|c|c|c|c|c|}
\hline \multirow[t]{2}{*}{ Variável meteorológica } & \multicolumn{5}{|c|}{$\begin{array}{c}\text { Periodo que antecede a colheita } \\
\text { (em dias) }\end{array}$} \\
\hline & $1-15$ & $16-30$ & $31-45$ & $46-60$ & $61-75$ \\
\hline \multicolumn{6}{|c|}{ Peso do hectolitro } \\
\hline Precipitação pluvial & $-0,30$ & $-0,37$ & - & - & - \\
\hline Umidade relativa do ar & - & - & - & - & - \\
\hline \multicolumn{6}{|c|}{ Peso de mil grãos } \\
\hline Precipitação pluvial & $-0,31$ & $-0,37$ & $-0,32$ & - & - \\
\hline \multicolumn{6}{|c|}{ Rendimento de grãos } \\
\hline Precipitação pluvi & - & $-0,35$ & - & - & - \\
\hline Umidade relativa do ar & - & - & - & - & - \\
\hline
\end{tabular}

$\operatorname{dez}(\mathrm{r}=-0,41)$ e onze a vinte $(\mathrm{r}=-0,30)$ dias antes da colheita, enquanto o rendimento de grãos foi afetado por essa variável nos períodos de onze a vinte $(r=-0,34)$ e sessenta e um a setenta $(r=-0,31)$ dias anteriores à colheita (Tabela 3). Por sua vez, o peso de mil grãos foi influenciado negativamente pelo excesso hídrico do solo, nos periodos de trinta e um a quarenta dias $(\mathrm{r}=-0,36)$ e cinqüenta e um a sessenta $(r=-0,35)$ dias anteriores à colheita (Tabela 3). O excesso hídrico do solo reduziu o rendimento de grãos no período de sessenta e um a setenta $(r=-0,31)$ dias anteriores à colheita e o peso do hectolitro no período de setenta e um a oitenta $(\mathrm{r}=-0,35)$ dias anteriores à colheita (Tabela 3).

Observou-se que a média da umidade relativa do ar
TABELA 5 - Sumário das correlações múltiplas $(p<0,05)$ entre variáveis meteorológicas e características de qualidade e rendimento de trigo Embrapa 16, no período de um a oitenta dias que antecedem a colheita, divididos em vinte em vinte dias

\begin{tabular}{|c|c|c|c|c|}
\hline \multirow[t]{2}{*}{ Variável meteorológica } & \multicolumn{4}{|c|}{$\begin{array}{c}\text { Periodo que antecede a colheita } \\
\text { (em dias) }\end{array}$} \\
\hline & $1-20$ & $21-40$ & $41-60$ & $61-80$ \\
\hline \multicolumn{5}{|c|}{ Peso do hectolitro } \\
\hline Precipitação pluvial & $-0,34$ & - & - & - \\
\hline Umidade relativa do ar & 5 & - & - & - \\
\hline \multicolumn{5}{|c|}{ Peso de mil grãos } \\
\hline Precipitação pluvial & $-0,32$ & $-0,33$ & - & - \\
\hline Umidade relativa do ar & - & $-0,35$ & - & - \\
\hline \multicolumn{5}{|c|}{ Rendimento de grãos } \\
\hline Precipitação pluvial & - & - & - & - \\
\hline Umidade relativa do ar & - & - & - & - \\
\hline
\end{tabular}

influenciou positivamente o peso do hectolitro, nos períodos de cinqüenta e seis a sessenta $(r=0,30)$ e cinqüenta e um a sessenta dias anteriores à colheita $(\mathrm{r}=0,32)$, Tabelas 2 e 3, respectivamente. No entanto, essa mesma variável meteorológica afetou negativamente $(r=-0,27) \mathrm{o}$ peso do hectolitro no período de vinte e um a trinta dias anteriores à colheita (Tabela 3).

O peso de mil grãos foi negativamente correlacionado com a média da umidade relativa do ar nos periodos de um a cinco $(r=-0,39)$, trinta e seis a quarenta $(\mathrm{r}=-0,32)$, vinte e um a trinta $(\mathrm{r}=-0,36)$ e vinte e um a quarenta dias anteriores à colheita $(\mathrm{r}=-0,35)$, (Tabelas 2,3 e 5). 
O déficit hídrico do solo influenciou negativamente o peso do hectolitro nos periodos de quarenta e um a cinqüenta $(r=-0,41)$ e cinqüenta e um a sessenta dias $(r=-0,56)$ anteriores à colheita (Tabela 3). Também no período de quarenta e um a cinqüenta dias anteriores à colheita, o rendimento de grãos foi afetado $(r=-0,29)$ pelo déficit hídrico do solo (Tabela 3). O peso de mil grãos foi influenciado positivamente pelo déficit hídrico do solo no periodo de um a dez dias anteriores à colheita $(r=0,34)$, conforme consta na Tabela 3.

Neste trabalho, no período estimado de enchimento de grãos, ou seja, no período compreendido entre sessenta e dez dias antes da colheita, os resultados obtidos parecem indicar a influência dessas variáveis meteorológicas no peso do hectolitro, no peso de mil grãos e no rendimento de grãos. Isso pode ser explicado pelo mecanismo que mostra a interferência destas variáveis meteorológicas na sintese de produtos fotossintéticos que promovem o enchimento de grãos.

Relativamente a esse assunto, BERGAMASCHI [2] relata que o equilíbrio hídrico de uma planta é dado pela diferença entre as taxas de entrada (absorção de água) e de perda de água (transpiração). A condição de suprimento de água resulta na interação que se estabelece no sistema solo-planta-atmosfera. As influências reciprocas entre esses três componentes básicos tornam o sistema dinâmico e fortemente interligado, de tal forma que a condição hídrica da cultura dependerá sempre da combinação de fatores inerentes aos três segmentos.

Complementando a informação acima citada, REICHARDT [30] explica que, sob condições de elevada umidade relativa e na ausência de vento, o processo de difusão é lento e a perda de água é pequena. Quando os estômatos estão fechados, a transpiração diminui sensivelmente, podendo até tornar-se desprezivel. Em condições isotérmicas, de uma atmosfera saturada de água, quando houver precipitação pluvial e a umidade relativa for elevada, e de uma planta túrgida, não há fluxo de água na planta. Não ocorrendo fluxo de água na planta e, conseqüentemente, de nutrientes, há redução de produtos fotossintéticos, como carboidratos, lipídios, aminoácidos etc., responsáveis pelo enchimento de grãos. Isso poderia explicar os resultados encontrados indicando que, de acordo com esse mecanismo, os grãos tornar-se-iam menores, de reduzidos peso de mil grãos e peso do hectolitro e, conseqüentemente, afetariam o rendimento de grãos.

HIRANO [19] mostra que o mecanismo da deterioração da qualidade industrial de trigo em razão de chuva ocorrida em periodos de mais de 20 dias antes da colheita é conseqüência de decréscimo do enchimento de grãos, resultante de redução na acumulação da matéria seca causada por redução da fotossíntese e da absorção de nutrientes. Os grãos tornam-se chochos, e o peso do hectolitro e o peso de mil grãos decrescem. Dados obtidos neste trabalho podem indicar resultados similares aos encontrados por esse autor. Alguns, a influência negativa da precipitação pluvial no peso do hectolitro e no peso de mil grãos, observada em períodos de mais de vinte dias anteriores à colheita.

A diminuição do peso do hectolitro pode ser atribuída às mudanças sucessivas na umidade do grão, produto das aplicações de água [22]. Da mesma forma, FINNEY \& YAMAZAKI [17] assinalaram que o umedecimento e a secagem do grão de trigo reduzem o peso do hectolitro, como conseqüência da diminuição de densidade. Essas deduções também podem explicar os resultados encontrados neste trabalho.

Com relação ao rendimento de grãos, pode-se especular que os resultados obtidos são devidos ao estresse por água, que provoca a modificação de estruturas vegetativas da planta, como a área foliar, a qual determina a capacidade fotossintética [16], ou, então, à redução do número de grãos desenvolvidos [5].

No entanto, após o período de maturação fisiológica da planta, aproximadamente dez dias anteriores à colheita, a redução do peso do hectolitro, do peso de mil grãos e do rendimento de grãos pode ser devida à germinação pré-colheita.

Nos casos de grãos que germinaram antes da colheita, a diminuição do rendimento de grãos, do peso de mil grãos e do peso do hectolitro é devida à elevada taxa de respiração, a qual consome carboidratos acumulados nos grãos [3]. Essa teoria também pode explicar os resultados obtidos neste trabalho.

\section{4 - CONCLUSÕES}

- A precipitação pluvial e o excesso hídrico do solo afetaram negativamente o peso do hectolitro, o peso de mil grãos e o rendimento de grãos;

- a umidade relativa do ar apresentou menor influência no peso do hectolitro, no peso de mil grãos e no rendimento de grãos, comparativamente às demais variáveis analisadas, no entanto, quando essa influência aconteceu, tanto foi positiva quanto negativa;

- o déficit hídrico do solo afetou positivamente o peso do hectolitro, o peso de mil grãos e o rendimento de grãos após a maturação fisiológica, isto é, nos dez primeiros dias anteriores à colheita, e negativamente nos demais períodos.

\section{5 - REFERÊNCIAS BIBLIOGRÁFICAS}

[1] BALANÇAS DALLE MOLLE (Caxias do Sul). Instruções para montagem da balança de peso específico. Caxias do Sul, [19- -].

[2] BERGAMASCHI,H. Desenvolvimento de déficit hídrico em culturas. In: BERGAMASCHI, H.Coord. Agrometeorologia aplicada à irrigação. Porto Alegre: Editora da Universidade /UFRGS, 1992. Cap.1:p.25-32.

[3] BHAT, G.M.; PAULSEN, G.M.; KULP, K; HEYNE, E.G. Cereal Chemistry, St. Paul, v.58, n.4, p.300-302, Jul.,1981. 
[4] BRASIL. Ministério da Agricultura e da Reforma Agrária. Secretaria Nacional de Defesa Agropecuária. Regras de análises para sementes. Brasília, 1992. p.194-195.

[5] CLASSEN, M.M.; SHAW, R.H. Water deficit effects on corn. I. Vegetative components. Agronomy Journal, Madison, v.62, n.5, p.649-652, 1970.

[6] CUNHA, G.R. Meteorologia: fatos \& mitos. Passo Fundo: EMBRAPA-CNPT, 1997.268p.

[7] DÁVAlOS, E.D.; PACHECO, A.C.; HENNIGEN, J. Avaliação de cultivares de trigo em Santa Catarina 1998. Chapecó: EPAGRI Centro de Pesquisa para Pequenas Propriedades, 1999. 15p. Trabalho apresentado na XXXI Reunião da Comissão SulBrasileira de Pesquisa de Trigo, Passo Fundo, 1999.

[8] DÁVAlOS, E.D.; PACHECO, A.C.; HENNIGEN, J.; MACHADO, E.O. Avaliação de cultivares de trigo em Santa Catarina - 1991. In: REUNIÃO DA COMISSÃO SUL-BRASILEIRA DE PESQUISA DE TRIGO, 24., 1992, Cruz Alta. Ata... Cruz Alta: FUNDACEP - FECOTRIGO Fundação Centro de Experimentação e Pesquisas FECOTRIGO, 1992.p.22.

[9] DÁVAlOS, E.D.; PACHECO, A.C.; HENNIGEN, J.; MACHADO, E.O. Avaliação de cultivares de trigo em Santa Catarina - 1993. Chapecó: EPAGRI Centro de Pesquisa para Pequenas Propriedades, 1994. 13p. Trabalho apresentado na XXVI Reunião da Comissão Sul-Brasileira de Pesquisa de Trigo, Chapecó, 1994.

[10] DÁVALOS, E.D.; PACHECO, A.C.; HENNIGEN, J.; MACHADO, E.O. Avaliação de cultivares de trigo em Santa Catarina - 1994. Chapecó: EPAGRI Centro de Pesquisa para Pequenas Propriedades, 1995. $17 \mathrm{p}$. Trabalho apresentado na XXVII Reunião da Comissão Sul-Brasileira de Pesquisa de Trigo, Porto Alegre, 1995.

[11] DÁVAlOS, E.D.; PACHECO, A.C.; HENNIGEN, J.; MACHADO, E.O. Avaliação de cultivares de trigo em Santa Catarina - 1995. Chapecó: EPAGRI Centro de Pesquisa para Pequenas Propriedades, 1996. 19p. Trabalho apresentado na XXVIII Reunião da Comissão Sul-Brasileira de Pesquisa de Trigo, Passo Fundo, 1996.

[12] DÁVAlOS, E.D.; PACHECO, A.C.; HENNIGEN, J.; MACHADO, E.O. Avaliação de cultivares de trigo em Santa Catarina - 1996. Chapecó: EPAGRI Centro de Pesquisa para Pequenas Propriedades, 1997. 20p. Trabalho apresentado na XXIX Reunião da Comissão Sul-Brasileira de Pesquisa de Trigo, Porto Alegre, 1997.

[13] DÁVAlOS, E.D.; PACHECO, A.C.; HENNIGEN, J.; MACHADO, E.O. Avaliação de cultivares de Trigo em Santa Catarina - 1997. Chapecó: EPAGRI Centro de Pesquisa para Pequenas Propriedades, 1998. 17p. Trabalho apresentado na XXX Reunião da Comissão Sul-Brasileira de Pesquisa de Trigo, Chapecó, 1998.

[14] DEL DUCA, L.J.A. Influência da seleção natural, comparação de métodos de melhoramento genético e avaliação precoce em populações segregantes de trigo (Triticum aestivum L.). Porto Alegre, 1991. 258p. Tese (Doutor em Ciências) - Departamento de Genética, Universidade Federal do Rio Grande do Sul.

[15] DEL DUCA, L.J.A.; SOUSA, C.N.A. DE; GOMES, E.P.; GUARIENTI, E.M.; MOREIRA, J.C.S.; SARTORI, J.F.; MEDEIROS, M.; SCHEEREN, P.L. Descrição do desempenho da cultivar de trigo Embrapa 16, recomendada para o Rio Grande do Sul e para Santa Catarina. Passo Fundo: CNPT - Centro Nacional de Pesquisa de Trigo, 1994. p.121. Trabalho apresentado na XVII Reunião Nacional de Pesquisa de Trigo, Passo Fundo, 1994.

[16] DUBETZ, S.; BOLE, J.B. Effects of moisture stress at early heading and of nitrogen fertilizer on three spring wheat cultivars. Canadian Journal of Plant Science, Ottawa, v.53, n.1, p.1-5, Jan.,1973.

[17] FINNEY, K.; YAMAZAKI, W. Quality of hard, soft and durum wheats. In: QUINSENBERRY, K.S.; REITZ, L.P., ed. Wheat and wheat improvement. Madison: American Society of Agronomy, 1967. Chap.14, p.471503. (Agronomy, 13).

[18] HADJICHRISTODOULOU, A. The effects of annual precipitation and its distribution on grain yield of dryland cereals. Journal of Agricultural Science, Cambridge, v.99, n.2, p.261-270, Oct., 1982.

[19] HIRANO, J. Effects of rain in ripening period on the grain quality of wheat. Japan Agricultural Research Quarterly, Ibaraki, v.10, n.4, p.168-173, Oct., 1976.

[20] KOLDERUP, F. Effects of temperature, photoperiod, and light quantity on yield capacity of wheat. Meldinger fra Norges Landbrukshegskole, v.53, n.36, p.1-10, 1974.

[21] LUZ, W.C. da. Efeito da precipitação pluviométrica no rendimento de duas cultivares de trigo. Pesquisa Agropecuária Brasileira, Brasília, v.17, n.3, p.351-354, mar., 1982.

[22] MELLADO Z., M.; MALDONADO I., I.; GRANGER Z.,D. Efecto de la lluvia, posterior a la madurez de cosecha, sobre el grano de trigo. Agricultura Tecnica, Santiago, v.45, n.3, p.247-251, jul./septiembre, 1985.

[23] MOREIRA, J.C.S. Resultados dos Ensaios SulBrasileiros de Trigo no Rio Grande do Sul, em 1990. Passo Fundo: EMBRAPA CNPT, Centro Nacional de Pesquisa de Trigo, 1991. 19p. Trabalho apresentado na XXIII Reunião da Comissão Sul-Brasileira de Pesquisa de Trigo, Pelotas, 1991.

[24] MOREIRA, J.C.S. Resultados dos Ensaios SulBrasileiros de Trigo no Rio Grande do Sul, em 1996. Passo Fundo, EMBRAPA CNPT, 1997. 25p. (EMBRAPA-CNPT. Documentos, 32). Trabalho apresentado na XXIX Reunião da Comissão SulBrasileira de Pesquisa de Trigo, Porto Alegre, 1997.

[25] MOREIRA, J.C.S. Resultados dos Ensaios SulBrasileiros de Trigo no Rio Grande do Sul, em 1995. Passo Fundo, EMBRAPA CNPT, 1996. 27p. (EMBRAPA-CNPT. Documentos, 25). Trabalho apresentado na XXVIII Reunião da Comissão SulBrasileira de Pesquisa de Trigo, Passo Fundo, 1996.

[26] MOREIRA, J.C.S. Resultados dos Ensaios SulBrasileiros de Trigo no Rio Grande do Sul, em 1991. Passo Fundo, EMBRAPA CNPT, 1992. 24p. (EMBRAPA-CNPT. Documentos, 1). Trabalho apresentado na XXIV Reunião da Comissão SulBrasileira de Pesquisa de Trigo, Cruz Alta, 1992.

[27] MOREIRA, J.C.S. Resultados dos Ensaios SulBrasileiros de Trigo no Rio Grande do Sul, em 1994. Passo Fundo, EMBRAPA CNPT, 1995. 28p. 
(EMBRAPA-CNPT. Documentos, 20). Trabalho apresentado na XXVII Reunião da Comissão SulBrasileira de Pesquisa de Trigo, Porto Alegre, 1995.

[28] MOTA, F.S. Clima e zoneamento para a triticultura no Brasil. Pelotas: UFPel, 1980. 32p. (UFPel. Boletim Técnico, 3).

[29] PUZZI, D. Padronização de cereais, grãos leguminosos e café. In: PUZZI, D. Abastecimento e armazenagem de grãos. Campinas: Instituto Campineiro de Ensino Agrícola, 1986. Cap. 22: p.573-580.

[30] REICHARDT, K. A água: absorção e translocação. In: FERRI, M.G. coord. Fisiologia vegetal. São Paulo: Editora Pedagógica e Universitária Ltda., 1985. v.1 Cap.1: p.3-24.

[31] ROLIM, G.S.; SENTELHAS, P.C.; BARBIERI, V. Planilhas no ambiente Excel ${ }^{\mathrm{TM}}$ para os cálculos de balanços hídricos: normal, seqüencial, de cultura e de produtividade real e potencial. Revista Brasileira de Agrometeorologia, Santa Maria, v.6, n.1, p.133-137, jan., 1998.

[32] SEIF, E.; PEDERSON, D.G. Effect of rainfall on the grain yield of spring wheat, with an application to the analyses of adaptation. Australian Journal of Agricultural Research, Victoria, v.29, n.5, p.1107-1115, Sept., 1978.

[33] SOCIEDADE BRASILEIRA DE CIÊNCIA DO SOLO. Comissão de Fertilidade do Solo RS/SC. Recomendação de adubação e de calagem para os estados do Rio Grande do Sul e de Santa Catarina. 3ed. Passo Fundo, 1995. 223p.

[34] SVOBODA, L.H.; TONON, V.D.; NETO, N.; MATZENBACHER, R.G. Resultados do Ensaio Regional de Linhagens de Trigo no Rio Grande do Sul, em 1996. Cruz Alta: FUNDACEP Fundação Centro de Experimentação e Pesquisa FECOTRIGO, 1997. 17p. Trabalho apresentado na XXIX Reunião da Comissão Sul-BRASILeira de Pesquisa de Trigo, Porto Alegre, 1997.

[35] SVOBODA, L.H.; TONON, V.D.; NETO, N.; MATZENBACHER, R.G. Resultados do Ensaio Regional de Linhagens de Trigo no Rio Grande do Sul, em 1994. Cruz Alta: FUNDACEP Fundação Centro de Experimentação e Pesquisa FECOTRIGO, 1995. 25p.
Trabalho apresentado na XXVII Reunião da Comissão Sul-Brasileira de Pesquisa de Trigo, Porto Alegre, 1995.

[36] THORNTHWAITE, C.; MATHER, R.J. The water balance. New Jersey: Laboratory of Climatology, 1955. V.8, 104p. (Publication in Climatology).

[37] WALDMAN, L.; CAUMO, A. Resultados do Ensaio Estadual de Cultivares de Trigo no Rio Grande do Sul, em 1994. Porto Alegre: FEPAGRO Fundação Estadual de Pesquisa Agropecuária, 1995. 22p. Trabalho apresentado na XVII Reunião da Comissão Sul-Brasileira de Pesquisa de Trigo, Porto Alegre, 1995.

[38] WALDMAN, L.; CAUMO, A.; MAIRESSE, L.A.S.; ZANOTELLI, V. Resultados do Ensaio Estadual de Cultivares de Trigo no Rio Grande do Sul, em 1993. Porto Alegre: IPAGRO-CIENTEC Instituto de Pesquisas Agronômicas, 1994. 24p. Trabalho apresentado na XIV Reunião da Comissão Sul-Brasileira de Pesquisa de Trigo, Chapecó, 1994.

[39] WILLIAMS, G.D.V. Estimates of prairie provincial wheat yields based on precipitation and potential evapotranspiration. Canadian Journal of Plant Science, Ottawa, v.53, n.1, p.17-30, jan., 1973.

[40] ZANOTELLI, V.; LOSSO, A.C.; BERTOLDO, N.; TOMAZZI, D.; BELTRÃO, L. CAETANO, W. Ensaio Estadual de Cultivares de Trigo no Rio Grande do Sul, em 1998. Porto Alegre: FEPAGRO Fundação Estadual de Pesquisa Agropecuária, 1999. 18p. Trabalho apresentado na XXXI Reunião da Comissão SulBrasileira de Pesquisa de Trigo, Passo Fundo, 1999.

[41] ZANOTELLI, V.; LOSSO, A.C.; BERTOLDO, N.; TOMAZZI, D.; BELTRÃO, L. CAETANO, W. Ensaio Estadual de Cultivares de Trigo RS-1992. Porto Alegre: IPAGROCIENTEC Instituto de Pesquisas Agronômicas, 1993. 23p. Trabalho apresentado na XXV Reunião da Comissão Sul-Brasileira de Pesquisa de Trigo, Passo Fundo, 1993.

[42] ZANOTELLI, V.; LOSSO, A.C.; BERTOLDO, N.; TOMAZZI, D.; BELTRÃO, L. CAETANO, W. Ensaio Estadual de Cultivares de Trigo no Rio Grande do Sul, em 1997. Porto Alegre: FEPAGRO Fundação Estadual de Pesquisa Agropecuária, 1998. 20p. Trabalho apresentado na XXX Reunião da Comissão Sul-Brasileira de Pesquisa de Trigo, Chapecó, 1998. 